\title{
Concentrations and Profiles of Polychlorinated Dibenzo-p-Dioxins and Dibenzofurans in Air and Soil Samples in the Proximity of a Municipal Solid Waste Incinerator Plant
}

\author{
Wenbin Liu,, ${ }^{1, *}$ Wenjing Zhang, ${ }^{1,2}$ Sumei Li,, Chao Meng, ${ }^{1}$ Fang Tao, Haifeng Li,, and Bing Zhang \\ ${ }^{1}$ State Key Laboratory of Environmental Chemistry and Ecotoxicology, Research Center for Eco-Environmental Sciences, Beijing, China. \\ ${ }^{2}$ School of Safety and Environmental Engineering, Capital University of Economics and Business, Beijing, China.
}

Received: June 20, $2011 \quad$ Accepted in revised form: November 23, 2011

\begin{abstract}
This study investigated the influence of polychlorinated dibenzo-p-dioxins and dibenzofurans (PCDD/Fs) in the waste gas from an incinerator on the surrounding environment. A series of air and soil samples were collected at distances from 1.35 to $4.72 \mathrm{~km}$ from a typical municipal solid waste incineration plant along the prevailing north wind direction. Concentrations of $\mathrm{PCDD} / \mathrm{Fs}$ in the ambient air samples ranged from 0.23 to $1.66 \mathrm{pg}$ I-toxic equivalent (TEQ) $/ \mathrm{m}^{3}$, with an average of $0.82 \mathrm{pg} \mathrm{I}-\mathrm{TEQ} / \mathrm{m}^{3}$; while concentrations in the soil samples varied from 0.54 to $1.96 \mathrm{pg}$ I-TEQ/g, with an average of $1.33 \mathrm{pg} \mathrm{I}-\mathrm{TEQ} / \mathrm{g}$. Principal component analysis and hierarchical cluster analysis showed that the municipal solid waste incinerator has a potential influence on the environmental level of PCDD/Fs, and that emissions from traffic also play an important role.
\end{abstract}

Key words: ambient air; HCA; incineration; PCA; PCDD/Fs

\section{Introduction}

$\mathbf{P}$ OLYCHLORINATED DIBENZO-P-DIOXINS and dibenzofurans (PCDD/Fs) are among the persistent organic pollutants targeted for international source reduction by the Stockholm Convention. Exposure to PCDD/Fs is of great concern because of their toxicity, which may induce hormonedependent cancers and reproductive effects in humans and wildlife (Liu et al., 2005; Wang et al., 2010). Thermal or combustion processes, chemical-industrial sources, and reservoirs are the three important categories of dioxin sources. Of these, municipal solid waste incinerators (MSWIs) contribute most to environmental levels of PCDD/Fs (Breivik et al., 2004; Aurell et al., 2009b). As the largest developing country in the world, China generated 157 million tons of municipal solid waste (MSW) in 2009. The lack of landfill sites has led to incineration being an alternative effective and efficient means of treating waste. Consequently, the construction of incineration plants has boomed in China since 2000, and by 2009, 21.22 million metric tons of MSW were treated by incineration with a daily treatment capacity of 58,100 tons. The number of MSWIs is expected to reach 200 in 2015 with a total daily

${ }^{*}$ Corresponding author: State Key Laboratory of Environmental Chemistry and Ecotoxicology, Research Center for Eco-Environmental Sciences, P.O. Box 2871, Beijing 100085, China. Phone: +86 10 62849356; Fax: +86 10 62923563; E-mail: liuwb@rcees.ac.cn treatment capacity of 100,000 tons ( $\mathrm{Xu}$ et al., 2009a). Therefore, large amounts of PCDD/Fs will be annually released to the environment from MSWIs, causing increasing public concern over potential adverse environmental and health effects.

Researches on PCDD/F levels in ambient air and soil have been conducted in many countries in past decades, including Italy (Caserini et al., 2004), Japan (Takei et al., 2000), Spain (Schuhmacher et al., 1998, 2000; Domingo et al., 2001), the United States (Lorber et al., 1998, 2000), Korea (Oh et al., 2001, 2006; Lee et al., 2007), and Portugal (Coutinho et al., 2001). Until now, only limited investigations of atmospheric PCDD/ F pollution around MSWIs have been carried out in China. The available data (Cheng et al., 2003; Chao et al., 2004; Yu et al., 2006; Li et al., 2007, 2008a, 2008b; Wu et al., 2009) indicate that PCDD/F levels in some cities such as Shanghai, Guangzhou, and Hangzhou are comparable to or a little higher than those in other areas around the world.

The Cysunrise Municipal Solid Waste Incineration Plant (referred to hereafter as CY) is situated in China and has an annual treatment capacity of about 300,000 tons. This originally agricultural area now coexists with residential areas, in addition to schools and shopping malls, but with no heavy industry. PCDD/Fs emitted from the CY may impose negative health effects upon the surrounding residents. This study is expected to be helpful in estimating the PCDD/Fs released into the ambient environment and answering public concerns over the MSWIs. 


\section{Materials and Methods}

\section{Stack gas sampling}

Three stack gas samples were isokinetically collected from the $\mathrm{CY}$ stacks according to the Chinese national guidelines (HJ77.2) for PCDD/F emission analysis. Samples were collected using the ISO BASIC System (Tecora Corp.). The gaseous phase samples were collected by XAD-2 resin and condensed water, while the particulate phases were trapped by a quartzfiber filter (QFF). After sampling, the probe liners were washed with acetone and the washing solutions retained for analysis. All the analytical samples, consisting of the filter, XAD-2 resin, concentrated water and washing solution, were stored in darkness and analyzed as soon as possible after collection.

\section{Air and soil sampling}

Taking CY as the central point, nine sampling sites (A, B to I) were selected, broadly along the prevailing north wind direction, at distances from 1.35 (A) to 4.72 (F) km away. Ambient air and soil samples were collected at the same time from each site during the same period in December, 2010. During sampling the weather was cold and sunny with a moderate north breeze. Figure 1 shows the distribution of the sampling sites. Sampling sites A, B, and C were situated on the windward side of $\mathrm{CY}$, while sites $\mathrm{D}$ to I were on the leeward side.

Air concentration measurements were carried out with a high-volume sampler (Tecora Corp.) in compliance with US EPA Method TO-9A. Each air sample was collected over $48 \mathrm{~h}$, and total column volumes were $600-700 \mathrm{~m}^{3}$.The particulate matter was collected with a QFF and two polyurethane foam (PUF) traps were used to trap dioxins in the gas phase. After sampling, the QFF and PUF were separately wrapped in hexane-rinsed aluminum foil and stored in sealed PE bags. After transport to the laboratory, they were stored at $-20^{\circ} \mathrm{C}$ until analysis.

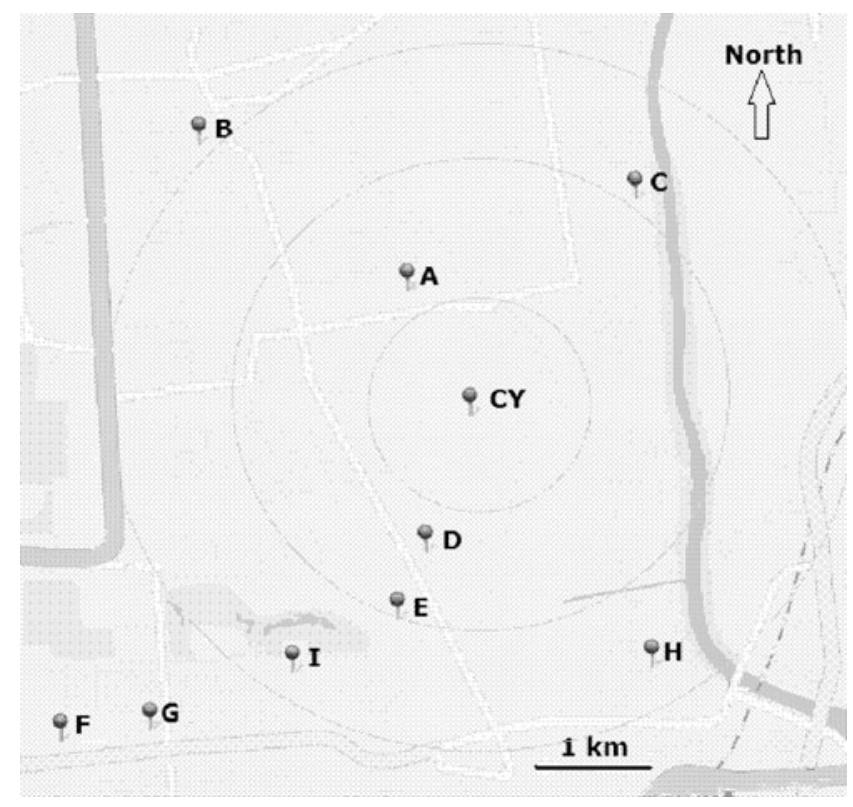

FIG. 1. Location of sampling sites around Cysunrise Municipal Solid Waste Incineration Plant.
Each soil sample was collected by mixing five different aliquots on the basis of the five plum distribution method within a $25 \mathrm{~m}^{2}$ area. About $2 \mathrm{~kg}$ of soil was collected with a metal hand-operated sampler, to a depth of about $5-15 \mathrm{~cm}$. After drying to constant weight, the samples were ground and homogenized through a 60-mesh sieve and refrigerated before analysis.

\section{Sample preparation and analysis}

The PCDD/F analysis was performed according to US EPA Method 1613 and EPA Compendium Method TO-9A. The detailed clean-up procedure is described elsewhere ( $\mathrm{Li}$ et al., $2008 \mathrm{~b})$. Briefly, the sample was spiked with $1 \mathrm{ng}$ of a ${ }^{13} \mathrm{C}_{12^{-}}$ labeled internal standard prior to accelerated solvent extraction (hexane:dichloromethane $=1: 1$ ). Then, the extract was sequentially cleaned by multilayer silica gel and basic alumina columns. The final extract was concentrated to $20 \mu \mathrm{L}$ and spiked with $1 \mathrm{ng}$ of the ${ }^{13} \mathrm{C}_{12}$-labeled injection standard for recovery quantification before analysis using HRGC/HRMS with a DB-5 column. The PCDD/Fs were quantified using Agilent 6890 gas chromatography coupled with an Autospec Ultima high-resolution mass spectrometer with an electron impact ion source. The HRMS was operated in SIM mode at $R \geq 10,000$. Field and laboratory blanks were incorporated into the analytical procedure for the purpose of quality control. The recovery range of 17 congeners of 2,3,7,8-PCDD/Fs was between 44.5 and $111.6 \%$, which met the limits of PCDD/Fs analysis.

\section{Results and Discussion}

\section{$P C D D / F s$ levels in the $C Y$ stack gas samples}

Figure 2 shows the I-toxic equivalent (TEQ) profiles of 2,3,7,8-PCDD/Fs in the stack gas samples.

The concentrations of $\mathrm{PCDD} / \mathrm{Fs}$ in the three stack gas samples were 1525.6, 1134.9 , and $587.2 \mathrm{pg} / \mathrm{m}^{3}$, and the corresponding TEQs were 98.5, 79.0, and 55.5 pg I-TEQ $/ \mathrm{m}^{3}$, respectively, calculated based on the International Toxic Equivalent Factors (I-TEFs). 2,3,4,7,8-PeCDF, 1,2,3,7,8-PeCDD, and $2,3,4,6,7,8-\mathrm{HxCDF}$ are the three major contributors to ITEQs, with 2,3,4,7,8-PeCDF being the single most important congener, regardless of the PCDD/F levels, accounting for $51.3 \%$ of the toxic equivalents.

It has been reported that homologue patterns are similar among various thermal processes, with PCDF percentages being higher than that of PCDDs (Hagenmaier et al., 1994; Buekens et al., 2000). Therefore, the PCDD/PCDF (D/F) ratio can serve as an indicator of contamination from thermal sources (Aurell et al., 2009a). In this study, the D/F ratios of three stack gas samples were $0.36,0.57$, and 0.77 , respectively. OCDD was the dominant homologue, accounting for $25.4 \%$ of the total concentration.

\section{PCDD/Fs levels in the ambient air samples}

Table 1 presents the levels of 2,3,7,8-PCDD/Fs in the ambient air samples.

The average I-TEQ value of PCDD/Fs in the ambient air samples was $0.82 \mathrm{pg} \mathrm{I}-\mathrm{TEQ} / \mathrm{m}^{3}$. The lowest was $0.23 \mathrm{pg} \mathrm{I-}$ $\mathrm{TEQ} / \mathrm{m}^{3}$ at site I, while the highest was $1.66 \mathrm{pg} \mathrm{I-TEQ} / \mathrm{m}^{3}$ at site B. Concentrations of 1,2,3,4,6,7,8-HpCDF, 1,2,3,4,6,7,8$\mathrm{HpCDD}, \mathrm{OCDF}$, and OCDD were relatively high in the air 


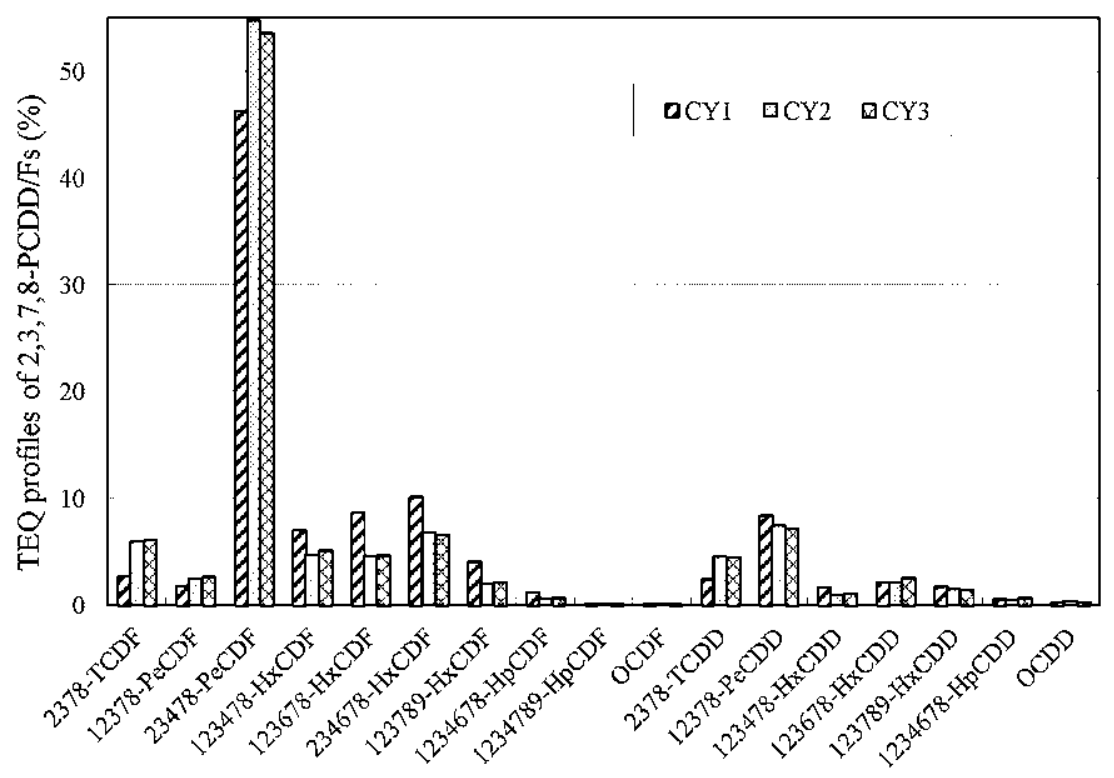

FIG. 2. TEQ profiles of 2,3,7,8-PCDD/Fs in the stack gas samples. PCDD/Fs, polychlorinated dibenzo-p-dioxins and dibenzofurans; TEQ, toxic equivalent.

samples. However, in terms of TEQ, 2,3,4,7,8-PeCDF and $1,2,3,7,8$-PeCDD were the dominant congeners, with average percentages of $31.56 \%$ and $10.72 \%$, respectively.

Until now, only limited investigations of atmospheric PCDD/F pollution around MSWIs have been carried out in China and concentrations were higher than measured in this study. Concentrations in air samples from Hangzhou ranged from 0.059 to $3.03 \mathrm{pg}$ I-TEQ $/ \mathrm{m}^{3}$ (Xu et al., 2009b), and in Guangdong the average value was $8.77 \mathrm{pg} \mathrm{I}-\mathrm{TEQ} / \mathrm{m}^{3}(\mathrm{Yu}$ et al., 2008). Comparison of PCDD/F concentrations in this study with globally reported values shows that they are at relatively high levels. Ambient air concentrations in three typical sites around different MSWIs in Italy were 0.010 $0.337 \mathrm{pg}$ I-TEQ $/ \mathrm{m}^{3}$ (Caserini et al., 2004), while concentrations in Oporto, Portugal, were $0.022-0.548 \mathrm{pg} \mathrm{WHO}-\mathrm{TEQ} / \mathrm{m}^{3}$
(Coutinho et al., 2001). A large variation in PCDD/F concen-

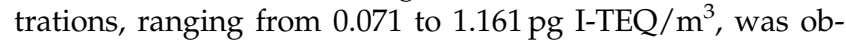
served in Korea (Oh et al., 2006).

$\mathrm{PCDD} / \mathrm{F}$ homologue profiles in the air at the various sampling sites are shown in Fig. 3. The sum of all homologue concentrations of PCDD/Fs varied between 6.89 and $96.31 \mathrm{pg} / \mathrm{m}^{3}$, with an average of $47.87 \mathrm{pg} / \mathrm{m}^{3}$. The lowest concentration was found at site I, with the highest at site D. Concentrations of PCDDs (range $2.26-31.75 \mathrm{pg} / \mathrm{m}^{3}$; average $14.41 \mathrm{pg} / \mathrm{m}^{3}$ ) are lower than the PCDFs (range $4.30-75.29 \mathrm{pg} / \mathrm{m}^{3}$; average $33.08 \mathrm{pg} / \mathrm{m}^{3}$ ). Lower-chlorinated homologues such as TCDD, TCDF, and PeCDF account for most of the total PCDD/F concentrations. The $\mathrm{D} / \mathrm{F}$ ratios in the air samples were between 0.28 and 0.78 , which are consistent with the results of the stack gas samples, showing PCDD/F emission characteristics

Table 1. Polychlorinated Dibenzo-p-Dioxins and Dibenzofuran Concentrations in the Ambient Air SAmples (PG/ $\left.{ }^{3}\right)$

\begin{tabular}{|c|c|c|c|c|c|c|c|c|c|}
\hline Isomer & $A$ & $B$ & C & $D$ & E & $F$ & $G$ & $H$ & $I$ \\
\hline $2,3,7,8-\mathrm{TCDF}$ & 0.17 & 0.23 & 0.13 & 0.31 & 0.4 & 0.28 & 0.09 & 0.73 & 0.12 \\
\hline $1,2,3,7,8-\mathrm{PeCDF}$ & 0.46 & 0.3 & 0.22 & 0.38 & 0.49 & 0.5 & 0.18 & 1.37 & 0.14 \\
\hline $2,3,4,7,8-\mathrm{PeCDF}$ & 0.47 & 0.32 & 0.26 & 0.56 & 0.66 & 0.59 & 0.23 & 0.28 & 0.19 \\
\hline $1,2,3,4,7,8-\mathrm{HxCDF}$ & 0.56 & 1.52 & 0.28 & 0.76 & 0.52 & 0.44 & 0.16 & 2.52 & 0.17 \\
\hline $1,2,3,6,7,8-\mathrm{HxCDF}$ & 0.5 & 1.4 & 0.29 & 0.74 & 0.55 & 0.47 & 0.16 & 1.81 & 0.17 \\
\hline $2,3,4,6,7,8-\mathrm{HxCDF}$ & 0.65 & 1.46 & 0.36 & 1.31 & 0.83 & 0.72 & 0.25 & 1.69 & 0.25 \\
\hline $1,2,3,7,8,9-\mathrm{HxCDF}$ & 0.27 & 1.22 & 0.08 & 0.17 & 0.28 & 0.18 & 0.06 & 0.88 & 0.06 \\
\hline $1,2,3,4,6,7,8-\mathrm{HpCDF}$ & 1.05 & 1.39 & 0.99 & 2.82 & 2.43 & 1.92 & 0.66 & 6.26 & 0.68 \\
\hline $1,2,3,4,7,8,9-\mathrm{HpCDF}$ & 0.44 & 1.43 & 0.18 & 0.22 & 0.33 & 0.28 & 0.11 & 3.05 & 0.11 \\
\hline OCDF & 1.27 & 2.33 & 0.6 & 0.8 & 1.24 & 1.23 & 0.41 & 5.32 & 0.77 \\
\hline $2,3,7,8-\mathrm{TCDD}$ & 0.04 & 0.17 & 0.01 & 0.16 & 0.04 & 0.04 & nd & 0.09 & 0.01 \\
\hline 1,2,3,7,8-PeCDD & 0.29 & 0.47 & 0.05 & 0.23 & 0.2 & 0.1 & 0.05 & 0.23 & 0.04 \\
\hline $1,2,3,4,7,8-\mathrm{HxCDD}$ & 0.26 & 1.27 & 0.03 & 0.4 & 0.09 & 0.05 & 0.03 & 0.22 & 0.03 \\
\hline $1,2,3,6,7,8-\mathrm{HxCDD}$ & 0.31 & 1.5 & 0.08 & 0.89 & 0.2 & 0.13 & 0.04 & 0.45 & 0.05 \\
\hline $1,2,3,7,8,9-\mathrm{HxCDD}$ & 0.38 & 1.73 & 0.08 & 0.73 & 0.16 & 0.13 & 0.04 & 0.33 & 0.05 \\
\hline $1,2,3,4,6,7,8-\mathrm{HpCDD}$ & 0.57 & 1.44 & 0.42 & 4.09 & 0.92 & 0.7 & 0.23 & 3.92 & 0.31 \\
\hline OCDD & 0.93 & 2.8 & 0.5 & 3.59 & 1.09 & 1.27 & 0.38 & 1.2 & 0.52 \\
\hline I-TEQ & 0.78 & 1.66 & 0.33 & 1.18 & 0.84 & 0.68 & 0.24 & 1.42 & 0.23 \\
\hline
\end{tabular}

TEQ, toxic equivalent; nd, not detected. 
FIG. 3. PCDD/F homologue profiles in the air at the various sampling sites.

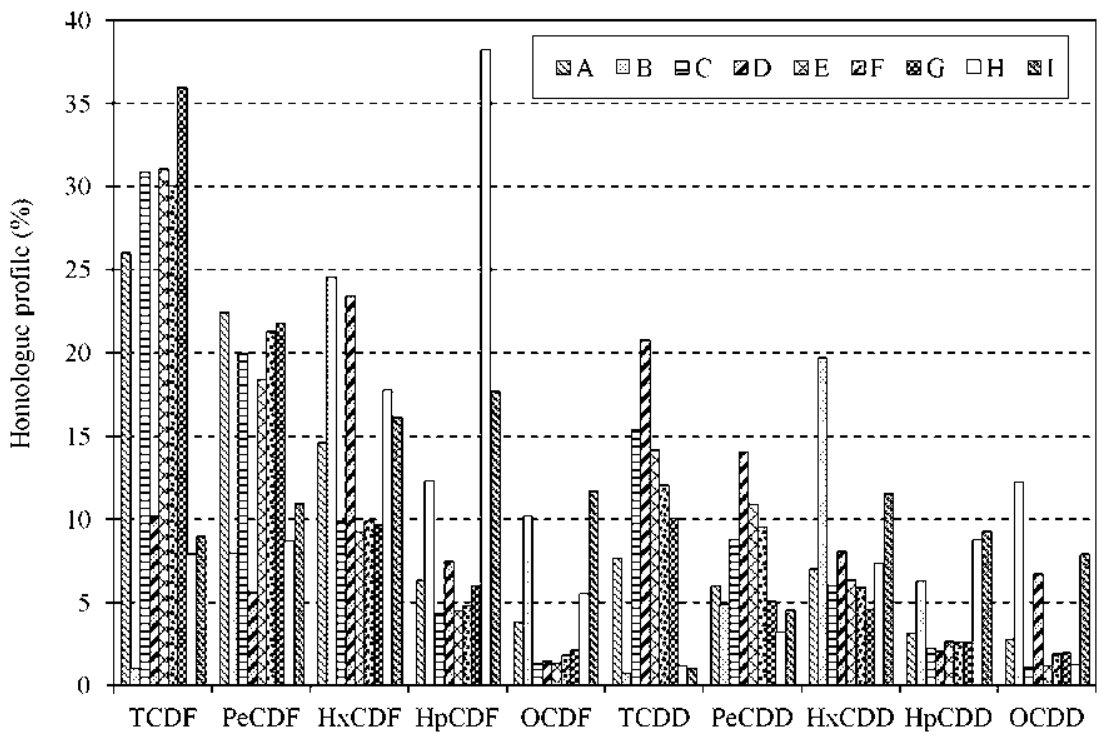

of thermal processes and suggesting a potential influence of the incineration plant on the surrounding environment.

\section{$P C D D / F s$ levels in the soil samples}

The levels of 2,3,7,8-PCDD/Fs in the ambient soil samples are presented in Table 2.

The average I-TEQ value of PCDD/Fs in the ambient soil samples was $1.33 \mathrm{pg}$ I-TEQ/g. The lowest values was $0.54 \mathrm{pg}$ I-TEQ/g at site I, while the highest was $1.96 \mathrm{pg}$ I-TEQ/g at site A. Low chlorinated congeners were the primary contributors to the total toxic equivalents. The corresponding average percentages of 2,3,4,7,8-PeCDF, 2,3,7,8-TCDD, and 1,2,3,7,8PeCDD were $29.22 \%, 12.30 \%$, and $11.21 \%$, respectively.

To gain perspective on the relative levels of PCDD/Fs in soils around the MSWI, the I-TEQ values were compared with those observed in a number of investigations worldwide. These showed large variations. Low concentrations of PCDD/Fs in soil samples, ranging from 0.08 to $1.5 \mathrm{pg}$ I-TEQ/g, were found in Italy (Caserini et al., 2004). Research conducted by Schuhmacher and Domingo in Spain showed similar low PCDD/F concentrations. However, in Barcelona, Spain, PCDD/F concentrations in soils ranged from 1.22 to $34.28 \mathrm{pg}$ I-TEQ/g (Schuhmacher et al., 2000). Data reported in the United States (Lorber et al., 1998, 2000) and Japan (Takei et al., 2000) were at quite high levels, with 4 and 7.1 pg I-TEQ/g as their average values. In Korea, PCDD/Fs in soil samples were between 1.25 and $74.98 \mathrm{pg}$ I-TEQ/g, which are much higher than those reported in other studies (Oh et al., 2006). PCDD/F concentrations in this study were moderate by comparison.

$\mathrm{PCDD} / \mathrm{F}$ homologue profiles in the soil samples from the various sampling sites are shown in Fig. 4. The average concentration of total PCDD/Fs in the soil samples was $62.45 \mathrm{pg} / \mathrm{g}$. The lowest concentration of total PCDD/Fs was $19.92 \mathrm{pg} / \mathrm{g}$

Table 2. Polychlorinated Dibenzo-P-Dioxins and Dibenzofuran Concentrations IN THE AMbient Soil SAmples (PG/G)

\begin{tabular}{|c|c|c|c|c|c|c|c|c|c|}
\hline Isomer & $A$ & $B$ & C & $D$ & E & $F$ & G & $H$ & $I$ \\
\hline $2,3,7,8-\mathrm{TCDF}$ & 0.33 & 0.71 & 0.35 & 0.15 & 0.38 & 0.71 & 0.73 & 1.65 & 0.38 \\
\hline $1,2,3,7,8-\mathrm{PeCDF}$ & 0.9 & 0.67 & 0.71 & 0.12 & 0.49 & 0.86 & 0.91 & 1.27 & 0.43 \\
\hline $2,3,4,7,8-\mathrm{PeCDF}$ & 1.17 & 0.54 & 1.11 & 0.28 & 0.92 & 0.76 & 0.93 & 0.72 & 0.36 \\
\hline $1,2,3,4,7,8-\mathrm{HxCDF}$ & 1.38 & 0.68 & 1.21 & 0.38 & 0.84 & 0.98 & 2.17 & 1.65 & 0.36 \\
\hline $1,2,3,6,7,8-\mathrm{HxCDF}$ & 0.58 & 0.33 & 0.73 & 0.53 & 0.64 & 1.09 & 1.11 & 2.02 & 0.35 \\
\hline $2,3,4,6,7,8-\mathrm{HxCDF}$ & 0.47 & 1.63 & 0.84 & 0.2 & 0.77 & 0.86 & 1.37 & 1.79 & 0.37 \\
\hline $1,2,3,7,8,9-\mathrm{HxCDF}$ & 0.67 & 0.7 & 0.47 & 0.03 & 0.1 & 0.11 & 0.62 & 0.13 & 0.05 \\
\hline $1,2,3,4,6,7,8-\mathrm{HpCDF}$ & 3.22 & 4.51 & 2.98 & 1.67 & 2.62 & 3.15 & 3.88 & 7.75 & 1.38 \\
\hline $1,2,3,4,7,8,9-\mathrm{HpCDF}$ & 0.37 & 0.45 & 0.96 & 0.14 & 0.25 & 0.46 & 0.6 & 0.92 & 0.15 \\
\hline OCDF & 2.79 & 1.81 & 2.96 & 1.55 & 1.43 & 3.58 & 3.06 & 5.91 & 2.03 \\
\hline $2,3,7,8-\mathrm{TCDD}$ & 0.57 & 0.29 & nd & 0.32 & nd & 0.04 & nd & 0.07 & 0.05 \\
\hline 1,2,3,7,8-PeCDD & 0.29 & 0.33 & 0.19 & 0.1 & 0.26 & 0.25 & 0.86 & 0.52 & 0.08 \\
\hline $1,2,3,4,7,8-\mathrm{HxCDD}$ & 0.73 & 0.31 & 0.54 & 0.07 & 0.18 & 0.15 & 1.05 & 0.44 & 0.07 \\
\hline 1,2,3,6,7,8-HxCDD & 0.63 & 1.07 & 2.07 & 0.22 & 0.32 & 0.24 & 0.75 & 0.75 & 0.18 \\
\hline 1,2,3,7,8,9-HxCDD & 0.46 & 0.02 & 0.47 & 0.15 & 0.69 & 0.26 & 0.61 & 0.68 & 0.18 \\
\hline 1,2,3,4,6,7,8-HpCDD & 4.68 & 4.3 & 2.77 & 0.89 & 1.9 & 2.15 & 3.63 & 6.52 & 2.9 \\
\hline OCDD & 8.79 & 8.25 & 9.8 & 3.97 & 7.25 & 7.53 & 7.7 & 5.98 & 7.23 \\
\hline I-TEQ & 1.96 & 1.41 & 1.43 & 0.72 & 1.06 & 1.10 & 1.87 & 1.83 & 0.54 \\
\hline
\end{tabular}




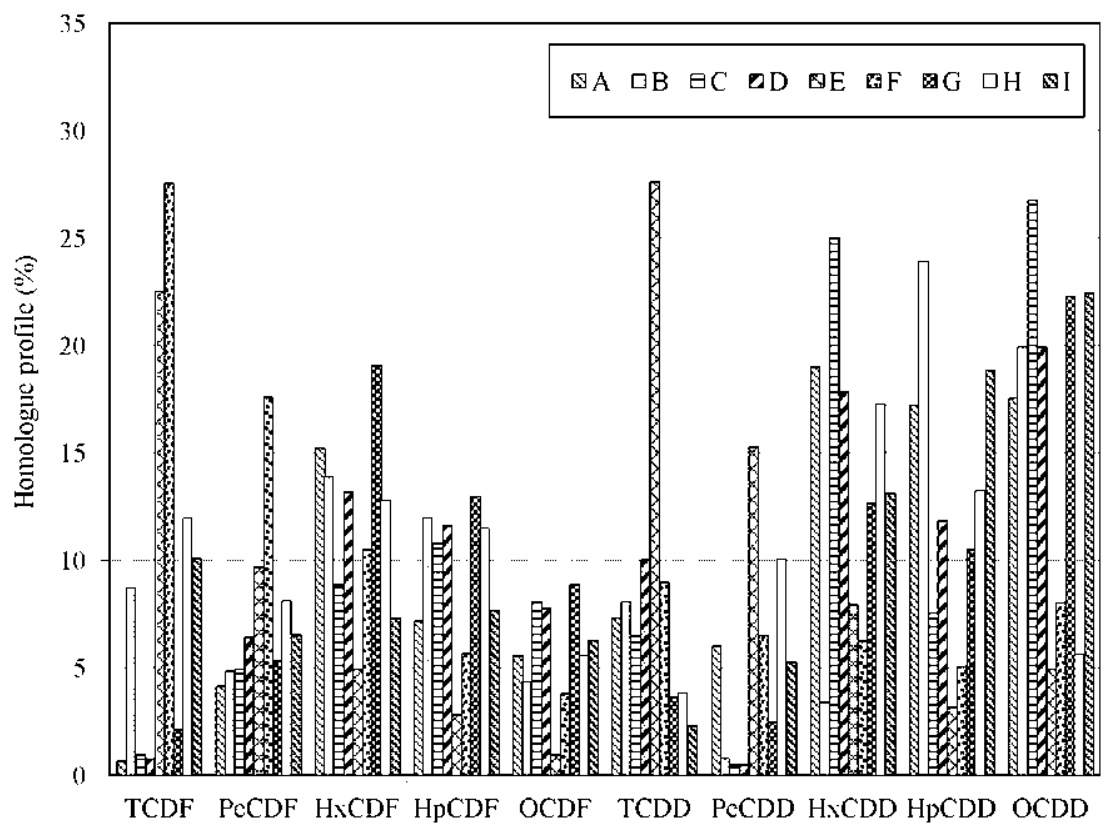

FIG. 4. PCDD/F homologue profiles in the soil samples.

found at site D, with a maximum of $147.26 \mathrm{pg} / \mathrm{g}$ at site E. High concentrations of PCDDs were found ranging from 11.99 to $86.89 \mathrm{pg} / \mathrm{g}$ with an average of $33.74 \mathrm{pg} / \mathrm{g}$, while PCDF concentrations ranged from 7.93 to $61.23 \mathrm{pg} / \mathrm{g}$ with an average of $28.71 \mathrm{pg} / \mathrm{g}$. OCDD, HxCDF, and HpCDD are the major contributors to the total concentration. The $\mathrm{D} / \mathrm{F}$ ratios in the soil samples were between 1.01 and 2.04, which are different from the air samples, because PCDDs, especially OCDD, are more stable than PCDFs and D/F ratios increased in the soil environment. Similar results were reported by some researches (Caserini et al., 2004; Xu et al., 2009a).

\section{$P C D D / F s$ source identification}

To identify the major PCDD/F sources that are responsible for the local environment, multivariate analyses, including principal component analysis (PCA) and hierarchical cluster analysis (HCA), were used in this study, summarizing the systematic information and providing relationships between PCDD/F levels in the various samples and emission sources. Although the CY is a noteworthy source of PCDD/Fs in the area, other potential dioxin emission sources such as traffic also should be taken into account (Anderson and Fisher, 2002; Joung et al., 2009; Xu et al., 2009a, 2009b). A congener-specific factor analysis with 17 congeners was performed using SPSS software, and nine ambient air samples, nine soil samples, and three stack gas samples were selected as the variables. In addition, three gas samples of traffic emissions in Guangzhou, China (Deng et al., 2011) were taken as variables.

The component plot of the factor loading clearly identified two principal components. These first and second principal components explain $75.2 \%$ and $15.4 \%$ of the total variance, respectively. The dendrogram plot of HCA is presented in Fig. 5. Almost all ambient air samples are clustered into a group except for sites B and D, while all soil samples, air samples in sites $B$ and D, three stack gas samples and three traffic gas samples constitute a main cluster. All the soil samples are clustered into a group in a very small rescaled distance and have a closer relationship with those emission sources than the

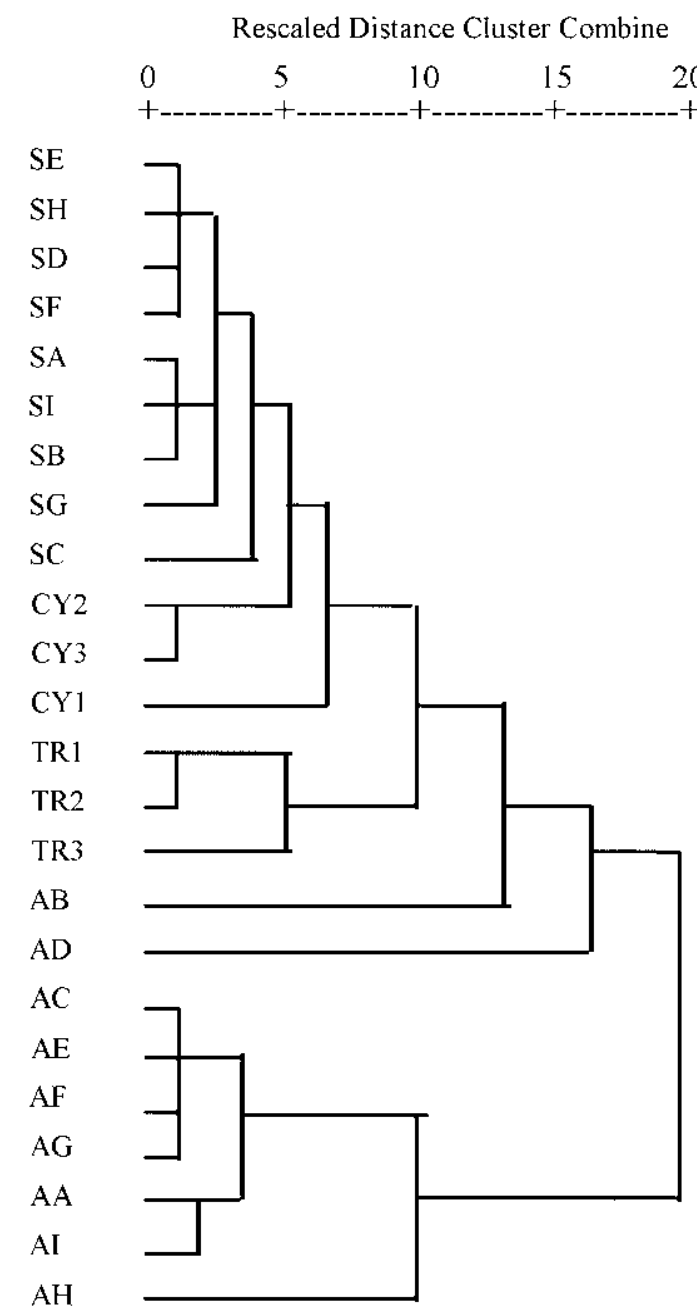

FIG. 5. Hierarchical tree plot of samples of air, soil, stack gas, and traffic. (The first letter represents the categories: A, air; $\mathrm{S}$, soil. The second letter represents the sampling sites. CY1-3, three stack gas samples of CY; TR1-3, three traffic gas samples). 
air samples. In ambient air samples, the quantity and variety of $\mathrm{PCDD} /$ Fs were more variable along with atmospheric transportation, such as dispersion and diffusion, while in the soil samples, PCDD/Fs exhibit a relatively stable pattern determined by emission sources. Further, in terms of the relationship between the samples and the presumed emission sources, the incineration has a potential influence on the environmental level of PCDD/Fs and traffic emissions may also play an important role in the environmental contamination.

\section{Acknowledgments}

This study was supported by the National 973 Program (2011CB201500) and the National Natural Science Foundation of China (20977099, 21077121).

\section{Author Disclosure Statement}

The authors declare that no financial conflicts exist.

\section{References}

Anderson, R.D., and Fisher, R. (2002). Sources of dioxins in the United Kingdom: the steel industry and other sources. Chemosphere 46, 371.

Aurell, J., Fick, J., and Marklund, S. (2009a). Effects of transient combustion conditions on the formation of polychlorinated dibenzo-p-dioxins, dibenzofurans, and benzenes, and polycyclic aromatic hydrocarbons during municipal solid waste incineration. Environ. Eng. Sci. 26, 509.

Aurell, J., Jansson, S., and Marklund, S. (2009b). Effects of quench time profiles on PCDD/F formation in the postcombustion zone during municipal solid waste incineration. Environ. Eng. Sci. 26, 541.

Breivik, K., Alcock, R., Li, Y., Bailey, R.E., Fiedler, H., and Pacyna, J.M. (2004). Primary sources of selected POPs: Regional and global scale emission inventories. Environ. Pollut. 128, 3.

Buekens, A., Cornelis, E., Huang, H., and Dewettinck, T. (2000). Fingerprints of dioxin from thermal industrial processes. Chemosphere 40, 1021.

Caserini, S., Cernuschi, S., Giugliano, M., Grosso, M., Lonati, G., and Mattaini, P. (2004). Air and soil dioxin levels at three sites in Italy in proximity to MSW incineration plants. Chemosphere 54, 1279.

Chao, M.R., Hu, C.W., Chen, Y.L., Chang-Chien, G.P., Lee, W.J., Chang, L.W., Lee, W.S., and Wu, K.Y. (2004). Approaching gas-particle partitioning equilibrium of atmospheric PCDD/ Fs with increasing distance from an incinerator: Measurements and observations on modeling. Atmos. Environ. 38, 1501.

Cheng, P.S., Hsu, M.S., Ma, E., Chou, U., and Ling, Y.C. (2003). Levels of PCDD/Fs in ambient air and soil in the vicinity of a municipal solid waste incinerator in Hsinchu. Chemosphere 52, 1389.

Coutinho, M., Ferreira, J., Gomes, P., Mata, P., and Borrego, C. (2001). Atmospheric baseline levels of PCDD and PCDF in the region of Oporto. Chemosphere 43, 497.

Deng, Y., Peng, P., Ren, M., Song, J., and Huang, W. (2011). The winter effect on formation of PCDD/Fs in Guangzhou by vehicles A tunnel study. Atmos. Environ. 45, 2541.

Domingo, J.L., Granero, S., and Schuhmacher, M. (2001). Congener profiles of $\mathrm{PCDD} / \mathrm{Fs}$ in soil and vegetation samples collected near to a municipal waste incinerator. Chemosphere $43,517$.

Hagenmaier, H., Lindig, C., and She, J. (1994). Correlation of environmental occurrence of polychlorinated dibenzo-p- dioxins and dibenzofurans with possible sources. Chemosphere $29,2163$.

Joung, H.T., Cho, S.J., Seo, Y.C., and Kim, W.H. (2009). Concentration of dioxin congeners in different phase products from a thermal process of end of life automobile shredder dusts. Environ. Eng. Sci. 26, 721.

Lee, S.J., Choi, S.D., Jin, G.Z., Oh, J.E., Chang, Y.S., and Shin, S.K. (2007). Assessment of PCDD/F risk after implementation of emission reduction at a MSWI. Chemosphere 68, 856.

Li, H., Feng, H., Sheng, G., Lu, S., Fu, J., Peng, P., and Man, R. (2008a). The PCDD/F and PBDD/F pollution in the ambient atmosphere of Shanghai, China. Chemosphere 70, 576.

Li, H., Yu, L., Sheng, G., Fu, J., and Peng, P. (2007). Severe $\mathrm{PCDD} / \mathrm{F}$ and $\mathrm{PBDD} / \mathrm{F}$ pollution in air around an electronic waste dismantling area in China. Environ. Sci. Technol. 41, 5641.

Li, Y., Jiang, G., Wang, Y., Cai, Z., and Zhang, Q. (2008b). Concentrations, profiles and gas-particle partitioning of polychlorinated dibenzo-p-dioxins and dibenzofurans in the ambient air of Beijing, China. Atmos. Environ. 42, 2037.

Liu, W., Zheng, M., Zhang, B., Qian, Y., Ma, X., and Liu, W. (2005). Inhibition of PCDD/Fs formation from dioxin precursors by calcium oxide. Chemosphere 60, 785.

Lorber, M., Eschenroeder, A., and Robinson, R. (2000). Testing the USA EPA's ISCST-Version 3 model on dioxins: A comparison of predicted and observed air and soil concentrations. Atmos. Environ. 34, 3995.

Lorber, M., Pinsky, P., Gehring, P., Braverman, C., Winters, D., and Sovocool, W. (1998). Relationships between dioxins in soil, air, ash, and emissions from a municipal solid waste incinerator emitting large amounts of dioxins. Chemosphere 37, 2173.

Oh, J.E., Choi, J.S., and Chang, Y.S. (2001). Gas/particle partitioning of polychlorinated dibenzo-p-dioxins and dibenzofurans in atmosphere; evaluation of predicting models. Atmos. Environ. 35, 4125.

Oh, J.E., Choi, S.D., Lee, S.J., and Chang, Y.S. (2006). Influence of a municipal solid waste incinerator on ambient air and soil PCDD/Fs levels. Chemosphere 64, 579.

Schuhmacher, M., Granero, S., Rivera, J., Muller, L., Lobet, J.M., and Domingo, J.L. (2000). Atmospheric deposition of PCDD/ Fs near an old municipal solid waste incinerator: Levels in soil and vegetation. Chemosphere 40, 593.

Schuhmacher, M., Granero, S., Xifro, A., Domingo, J. L., Rivera, J., and Eljarrat, E. (1998). Levels of PCDD/Fs in soil samples in the vicinity of a municipal solid waste incinerator. Chemosphere 37, 2127.

Takei, T., Araki, S., Kanai, M., and Morita, M. (2000). Environmental levels of dioxins in Japan: Results of nationwide survey of dioxins. Organhalogen Compd. 46, 475.

Wang, M., Chen, S., Huang, K., Lai, Y., Chang-Chien, G., and Tsai, J. (2010). Characterization of persistent organic pollutants emitted from a municipal solid waste incinerator in Taiwan. Environ. Eng. Sci. 27, 955.

Wu, Y., Lin, L., Hsieh, L.T., Wang, L., and Chang-Chien, G.P. (2009). Atmospheric dry deposition of polychlorinated dibenzo-p-dioxins and dibenzofurans in the vicinity of municipal solid waste incinerators. J. Hazard. Mater. 162, 521.

Xu, M., Yan, J., Lu, S., Li, X., Chen, T., Ni, M., Dai, H., Wang, F., and Cen, K. (2009a). Agricultural soil monitoring of PCDD/Fs in the vicinity of a municipal solid waste incinerator in Eastern China: Temporal variations and possible sources. J. Hazard. Mater. 166, 628. 
Xu, M., Yan, J., Lu, S., Li, X., Chen, T., Ni, M., Dai, H., Wang, F., and Cen, K. (2009b). Concentrations, profiles, and sources of atmospheric PCDD/Fs near a municipal solid waste incinerator in Eastern China. Environ. Sci. Technol. 43, 1023.

Yu, L., Li, H., Meng, X., Zhang, S., Ren, P., Sheng, G., and Fu, J. (2008). Effect of PCDD/Fs from electric waste combustion on the ambient atmospheric environment. Environ. Pollut. Contr. (China) 30, 8.

Yu, L., Mai, B., Meng, X., Bi, X., Sheng, G., Fu, J., and Peng, P. (2006). Particle-bound polychlorinated dibenzo-p-dioxins and dibenzofurans in the atmosphere of Guangzhou, China. Atmos. Environ. 40, 96. 